\title{
Sustained Perceptual Deficits from Transient Sensory Deprivation
}

\author{
- Melissa L. Caras and Dan H. Sanes \\ Center for Neural Science, New York University, New York, New York 10003
}

Sensory pathways display heightened plasticity during development, yet the perceptual consequences of early experience are generally assessed in adulthood. This approach does not allow one to identify transient perceptual changes that may be linked to the central plasticity observed in juvenile animals. Here, we determined whether a brief period of bilateral auditory deprivation affects sound perception in developing and adult gerbils. Animals were reared with bilateral earplugs, either from postnatal day 11 (P11) to postnatal day 23 (P23) (a manipulation previously found to disrupt gerbil cortical properties), or from P23-P35. Fifteen days after earplug removal and restoration of normal thresholds, animals were tested on their ability to detect the presence of amplitude modulation (AM), a temporal cue that supports vocal communication. Animals reared with earplugs from P11-P23 displayed elevated AM detection thresholds, compared with age-matched controls. In contrast, an identical period of earplug rearing at a later age (P23-P35) did not impair auditory perception. Although the AM thresholds of earplug-reared juveniles improved during a week of repeated testing, a subset of juveniles continued to display a perceptual deficit. Furthermore, although the perceptual deficits induced by transient earplug rearing had resolved for most animals by adulthood, a subset of adults displayed impaired performance. Control experiments indicated that earplugging did not disrupt the integrity of the auditory periphery. Together, our results suggest that P11-P23 encompasses a critical period during which sensory deprivation disrupts central mechanisms that support auditory perceptual skills.

Key words: auditory; critical period; development; hearing loss; otitis media; plasticity

\section{Significance Statement}

Sensory systems are particularly malleable during development. This heightened degree of plasticity is beneficial because it enables the acquisition of complex skills, such as music or language. However, this plasticity comes with a cost: nervous system development displays an increased vulnerability to the sensory environment. Here, we identify a precise developmental window during which mild hearing loss affects the maturation of an auditory perceptual cue that is known to support animal communication, including human speech. Furthermore, animals reared with transient hearing loss display deficits in perceptual learning. Our results suggest that speech and language delays associated with transient or permanent childhood hearing loss may be accounted for, in part, by deficits in central auditory processing mechanisms.

\section{Introduction}

Inadequate or abnormal sensory experience rapidly alters CNS structure and function, with the most profound effects arising from manipulations that occur during developmental critical periods (Es-

\footnotetext{
Received March 3, 2015; revised June 11, 2015; accepted June 24, 2015.

Author contributions: M.L.C. and D.H.S. designed research; M.L.C. performed research; M.L.C. analyzed data; M.L.C. and D.H.S. wrote the paper.

This work was supported by National Institutes of Health Grant R01DC014656 to D.H.S. We thank Dr. Edwin Rubel and Brandon Warren (University of Washington, Seattle) for ABR recording software, which was funded by National Institutes of Health Grant P30DC004661; Cindy Tsui for help with data collection; Ramanjot Kang for experimental assistance; and all members of the D.H.S. laboratory for their constructive criticism and support.

The authors declare no competing financial interests.

Correspondence should be addressed to Dr. Melissa L. Caras, New York University, Center for Neural Science, 4 Washington Place, New York, NY 10003. E-mail: caras@nyu.edu.

DOI:10.1523/JNEUROSCI.0837-15.2015

Copyright $\odot 2015$ the authors $\quad 0270-6474 / 15 / 3510831-12 \$ 15.00 / 0$
}

pinosa and Stryker, 2012; for review, see Erzurumlu and Gaspar, 2012; Kral et al., 2013). In the auditory system, the effects of early experience are generally assessed in adults, long after the sensory manipulation occurs. However, rapid hearing-dependent changes to neural function may undermine juvenile perceptual skills, yet resolve during maturation, leaving the false impression that deprivation caused little or no harm to behavior. In contrast, a developmental evaluation can reveal whether juvenile auditory deficits occur, and whether they resolve with additional time or practice. Therefore, we explored whether a brief period of auditory attenuation, which has been shown to profoundly alter cortical cellular and synaptic properties (Mowery et al., 2014), also induces deficits in juvenile auditory perception that outlast the period of deprivation.

Transient elevation of auditory thresholds are a significant concern for children. For example, children with a history of 
middle ear infections display auditory processing impairments, even if their peripheral sensitivity is normal at the time of testing (Moore et al., 1991; Pillsbury et al., 1991; Gravel and Wallace, 1992; Hogan and Moore, 2003; Tomlin and Rance, 2014). Similarly, children born with conductive hearing loss have difficulty understanding speech in noise well after corrective surgery (Wilmington et al., 1994). Although the majority of these perceptual deficits resolve by adulthood (Jerger and Johnson, 1988; Hall et al., 1995, 1998, 2003; Moore et al., 1996; Gravel et al., 2006), they increase the risk for long-term reading and writing difficulties (Gravel et al., 1996; Catts et al., 1999; Johnson et al., 1999) and behavioral problems (Brinton and Fujiki, 1993; Gertner et al., 1994; Beitchman et al., 1996). Thus, the long-term effects of transient hearing loss are significant and suggest that CNS dysfunction is a major contributing factor.

Transient auditory deprivation during development can degrade sound encoding and is closely associated with diminished perceptual skills. For example, temporary unilateral deprivation causes binaural encoding deficits that can account for behavioral impairments in sound localization and other binaural tasks (Clements and Kelly, 1978; Moore and Irvine, 1981; Knudsen et al., 1984b; Knudsen, 1985; Mogdans and Knudsen, 1992, 1993, 1994; Moore et al., 1999; Popescu and Polley, 2010; Keating et al., 2013, 2015; Polley et al., 2013). In addition, the clinical literature suggests that hearing loss can disrupt mechanisms associated with cognitive processing (Uhlmann et al., 1989; Arlinger, 2003; Lin et al., 2013). To address these issues, we asked whether a brief period of bilateral auditory deprivation affected sound perception and perceptual learning. Gerbils were assessed for their ability to detect amplitude modulation (AM), a cue that supports aural communication, including speech comprehension (Cazals et al., 1994; Shannon et al., 1995; Singh and Theunissen, 2003). The findings revealed that transient developmental deprivation disrupted AM detection and affected perceptual learning in a subject-specific manner.

\section{Materials and Methods}

Subjects. Male and female Mongolian gerbils (Meriones unguiculatus, $n=$ 93) were housed on a $12 \mathrm{~h}$ light $/ 12 \mathrm{~h}$ dark cycle. Pups were weaned from commercially obtained breeding pairs (Charles River) at postnatal day 30 (P30) and separated by sex into different cages. Food and water were available ad libitum unless otherwise noted. All procedures were approved by the Institutional Animal Care and Use Committee at New York University.

Transient auditory deprivation. Transient, bilateral auditory deprivation was induced by inserting malleable earplugs (BlueStik Adhesive Putty, RPM International or Silicone Elastomer, Sammons Preston Rolyan) into each ear canal (Mowery et al., 2014). Pups were restrained and positioned on a soft pad under a stereomicroscope (Olympus). The pinna was manipulated to allow for a clear view of the external auditory meatus, and curved, blunt forceps were used to insert each earplug. Earplugs were checked on a daily basis, and adjusted or reinserted, as necessary. Earplugs were left in place for $12 \mathrm{~d}$ (P11-P23 or P23-P35). On the day of earplug removal, the tympanic membrane was visualized and confirmed to be intact and clear of any residual debris. Sham littermates received identical handling and pinna manipulation (without earplug insertion).

An important caveat is that the hearing loss manipulation was not perfect: animals did occasionally lose earplugs, primarily due to the widening of the ear canal during development. To keep track of this uncontrolled variability, we noted how many $(0,1$, or 2$)$ earplugs were in place on each day. We then calculated an "earplug score" by determining the average number of earplugs that were in place each day for an individual animal. If an animal experienced "perfect" deprivation (i.e., the earplugs never fell out or moved out of place), the earplug score would be 2 . If both earplugs fell out every day, the animal's earplug score would be 0 . These earplug scores were later used to determine whether the stability of the earplugs could account for any of the variability in behavioral performance across animals (see Results).

Auditory brainstem response $(A B R)$ recording. ABRs were recorded to assess the attenuation induced by the earplug procedure and to assess peripheral status once the plugs were removed after an extended period of insertion $(12 \mathrm{~d})$. Animals were anesthetized with intraperitoneal injections of ketamine ( $30 \mathrm{mg} / \mathrm{kg}$; Bioniche Pharma) and pentobarbital (50 $\mathrm{mg} / \mathrm{kg}$; Sigma-Aldrich) and placed in a small sound booth (Industrial Acoustics). Supplemental anesthesia (20\% of induction dose) was delivered, as needed, to maintain a stable anesthetic state. Animal temperature was maintained at $37^{\circ} \mathrm{C}$ via a thermal rectal probe and digitally controlled heating blanket (Harvard Apparatus). Recordings were made by inserting pin electrodes subcutaneously at the vertex of the skull and just caudal to the right pinna; ground was inserted into the left leg. Voltage responses were amplified (10,000 gain) using a P15 or P55 model preamplifier (Grass Technologies). Signals were bandpass filtered $0.3-3 \mathrm{kHz}$, and an additional $32 \mathrm{~dB}$ of gain was introduced with a Brownlee Precision Model 440 amplifier (AutoMate Scientific) before digitizing at a 24.4 $\mathrm{kHz}$ sampling rate (RZ6, Tucker Davis Technologies) and acquiring on a PC (Dell) running Microsoft Windows 7.

Stimulus generation and data acquisition were controlled by custom Python scripts (provided by Brandon Warren and Edwin Rubel, University of Washington, Seattle). Stimuli were routed through an RZ6 multifunction processor (Tucker Davis Technologies), which performed both the digital-to-analog conversion and the signal attenuation, before delivery to a calibrated free-field speaker positioned $26 \mathrm{~cm}$ above the animal's head. Stimuli were $5 \mathrm{~ms}$ pure tones with $2 \mathrm{~ms}$ linear ramp rise-fall times. We presented seven frequencies $(0.5,1,2,4,6,8$, and $16 \mathrm{kHz})$, which span the subultrasonic region of the gerbil audiogram (Ryan, 1976). Each stimulus was presented at a rate of $23 / \mathrm{s}$ with alternating polarity. Tones were presented in $10 \mathrm{~dB}$ descending steps until the response disappeared, at which point the intensity was increased by $5 \mathrm{~dB}$ until a reliable response was observed ("threshold"). Traces were averaged across 250 sweeps, except near threshold, where 500 sweeps were averaged. Peak amplitudes were calculated as the absolute voltage difference between the wave peak and the following trough.

We labeled waves according to the nomenclature set forth by Burkard et al. (1993) (see Fig. 7A). According to Boettcher (2002), wave i of the gerbil ABR is homologous to wave I in humans, wave ii/iii in the gerbil is homologous to the human wave III, and gerbil wave iv is homologous to the human wave V. It is generally agreed that wave I of the human ABR (wave $\mathrm{i}$ here) is generated by the distal portion of the auditory nerve (Sohmer et al., 1974; Buchwald and Huang, 1975; Starr and Hamilton, 1976; Achor and Starr, 1980), Wave III in the human (wave ii/iii here) arises primarily from activity in the cochlear nucleus (Møller and Jannetta, 1983; Melcher and Kiang, 1996; Melcher et al., 1996), and the human wave $\mathrm{V}$ (wave iv here) reflects activity from multiple sources, including the cochlear nucleus, superior olivary complex, and lateral lemniscal tract (Hashimoto et al., 1981; Møller and Jannetta, 1982, 1983).

To determine whether earplugs disrupt cochlear frequency selectivity (Dolan et al., 1985), we implemented a forward masking paradigm. Probe tones ( $5 \mathrm{~ms}$ duration; $2 \mathrm{~ms}$ rise-fall; 4 and $6 \mathrm{kHz}$ ) were presented at $15 \mathrm{~dB}$ above each animal's threshold. Pure tone maskers (50 ms duration; $5 \mathrm{~ms}$ rise-fall) were presented at increasing intensities ( $5 \mathrm{~dB}$ steps) until the amplitude of the rising portion of the wave ii/iii complex (calculated from the preceding trough) of the probe response was reduced by at least $50 \%$. The masker level required to induce this reduction was considered the masker threshold. Masker frequencies were centered around the probe frequency in 1/8 octave intervals. The masker-probe interval remained constant at $5 \mathrm{~ms}$. Masker thresholds were used to construct frequency tuning curves. Tuning sharpness $\left(Q_{10}\right)$ was measured by dividing the probe frequency by the bandwidth $10 \mathrm{~dB}$ above the tip. Masker-probe combinations were presented at a fixed rate of $10 / \mathrm{s}$.

Behavioral training and testing. Animals performed a Go/NoGo procedure (Heffner and Heffner, 1995) used previously in our laboratory (Sarro and Sanes, 2010, 2011; Sarro et al., 2011; Rosen et al., 2012; Buran et al., 2014; Kang et al., 2014; Sarro and Sanes, 2014). Briefly, animals 


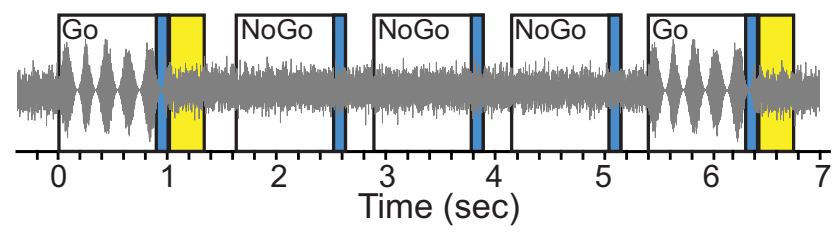

Figure 1. Schematic of AM detection task. Go stimuli (sinusoidal amplitude modulations at a rate of $5 \mathrm{~Hz}$ ) are embedded within a broadband noise carrier (gray oscillogram). Trials were presented approximately once a second as long as the animal made spout contact. Three to five NoGo trials were interspersed between each Go trial to avoid temporal conditioning. A response was scored as "withdrawal" if the animal broke contact with the spout for $\geq 50 \mathrm{~ms}$ during the last $100 \mathrm{~ms}$ of the trial (blue regions). A $300 \mathrm{~ms}$ aversive shock (yellow regions) followed each $G$ trial.

were placed in a test cage containing a stainless steel lick spout positioned above a metal floorplate. Spout contact was monitored via a $940 \mathrm{~nm}$ infrared LED (LTE 302, Lite On) and photodiode (OP950, Optek Technology) housed within a custom apparatus (Techwell Solutions). Interruption of the infrared beam triggered water delivery via a syringe pump (New Era Pump Systems). Sound stimuli were generated using a multifunction processor (RZ6; Tucker Davis Technologies) and delivered from a calibrated free-field speaker (DX25TG05-04; Vifa) positioned $1 \mathrm{~m}$ in front of the test cage. The test cage and speaker were housed within a sound-attenuating room (GretchKen) and monitored remotely via a closed-circuit video monitor. All aspects of the experiment were controlled using custom Python scripts developed in our laboratory (Dr. Bradley Buran).

Animals were initially trained to drink continuously while in the presence of steady, unmodulated, $60 \mathrm{~dB}$ SPL broadband noise with a lowfrequency fall off of $12 \mathrm{~dB} /$ octave at $2.5 \mathrm{kHz}$ and a high-frequency fall off of $12 \mathrm{~dB} /$ octave at $20 \mathrm{kHz}$. Animals then learned to withdraw from the lick spout when the noise transitioned from unmodulated to amplitude modulated (AM) by pairing the AM cue with a mild (0.5-1.0 mA), 300 ms electrical shock (Lafayette Instruments) delivered via the lick spout. The AM cue lasted for $1 \mathrm{~s}$ and consisted of a $5 \mathrm{~Hz}$ sinusoidal modulation (Fig. 1). The gain of the AM signal was adjusted to control for changes in average power due to changes in modulation depth (Viemeister, 1979; Wakefield and Viemeister, 1990). Responses were scored by determining whether the animal withdrew from the spout for at least $50 \mathrm{~ms}$ during the final $100 \mathrm{~ms}$ of the behavioral trial (Fig. 1, blue shaded regions). Withdrawals for $\geq 50 \mathrm{~ms}$ were procedurally defined as correct responses ("hits") on Go trials (AM noise), and incorrect responses ("false alarms"; [FAs]) on NoGo trials (unmodulated noise).

Animals were presented with a series of fully modulated (100\% AM depth) trials for the first few sessions. Go trials were randomly interspersed with 3 to 5 NoGo trials to avoid temporal conditioning. At the end of this procedural training, all animals had achieved a $d^{\prime} \geq 1.5$ for $100 \%$ depth (see Data analysis) and were moved on to the testing regimen. On the final day of procedural training, and throughout all testing sessions, the RMS stimulus intensity was held constant at $45 \mathrm{~dB}$ SPL. Each testing session began with a series of $100 \%$ depth "reminder trials" to ensure that the animal was motivated and willing to perform. Once animals responded correctly to 3 reminder stimuli in a row, a range of $5 \mathrm{AM}$ depths were presented in descending order (interspersed with NoGo trials, as above). Because the likely decision variable for amplitude modulation discrimination is logarithmic (Wakefield and Viemeister, 1990), depths were presented on a $\mathrm{dB}$ scale (re: $100 \%$ depth). Thus, $0 \mathrm{~dB}$ (re: $100 \%$ depth) refers to fully modulated (100\% depth) noise, and decreasing (negative) numbers refer to smaller depths. These values are not to be confused with dB SPL values, which indicate the RMS sound level of the stimulus. Within a session, consecutive depths always varied by $3 \mathrm{~dB}$.

Stimulus values were chosen to bracket the animal's likely threshold (procedurally defined as the AM depth that yielded a sensitivity of $d^{\prime}=$ 1 ), such that the three largest (easiest) of the five depths elicited $d^{\prime}$ values $\geq 1$, and the two lowest (hardest) of the five depths elicited a $d^{\prime}<1$. Based on the naive thresholds obtained in previous studies (Sarro and Sanes, 2010; Sarro et al., 2011; Rosen et al., 2012), we chose the following five depths to begin our initial test session: $0,-3,-6,-9$, and $-12 \mathrm{~dB}$ re: $100 \%$. After animals completed 8 trials at each depth within a session, behavioral performance was assessed online, and stimulus values were adjusted accordingly to maintain the threshold bracketing. An animal's final AM threshold for a session determined the 5 starting AM values for the next day.

Because individual animals vary in their sensitivity to pain (Mogil, 1999), shocks were adjusted for each subject to reliably elicit spout withdrawal, without dissuading the animal from resuming drinking shortly thereafter. Because the stimulus values were chosen each session to bracket the animal's threshold, it was likely that animals would fail to detect the smallest of the AM depths. If shocks were delivered during such trials, the animal would likely either stop drinking altogether, or would peck intermittently at the spout, resulting in a high FA rate. To avoid these possibilities, the shock was turned off for the lowest two depths presented. In a previous study, we validated the necessity of this approach and confirmed that animals do not become differentially conditioned to the presence or absence of the shock (Buran et al., 2014).

Data analysis. Behavioral sessions consisting of at least five different presentations of five different depths were analyzed. The percentage of "yes" responses (spout withdrawals) was plotted as function of modulation depth. These psychometric functions were fit using the maximum likelihood procedure of the open-source package psignifit for MATLAB (The MathWorks) (Wichmann and Hill, 2001a, b; Fründ et al., 2011). We found that a linear transform of modulation depths (i.e., the "mw0.1" core available in the bootstrap inference algorithm) fitted with a cumulative distribution function of the standard normal distribution provided a reasonable fit for the vast majority of our data. The formula for this function is as follows:

$$
\Psi(x ; m, w, \gamma, \lambda)=\gamma+(1-\gamma-\lambda) F(x ; m, w)
$$

where: $F(x ; m, w)=\Phi\left(\frac{z(\delta)}{w}(x-m)\right) ; z(\delta)=\Phi^{-1}(1-\delta)-\Phi^{-1}(\delta)$

and $\Phi$ is the inverse of the cumulative Gaussian. Here, $x$ represents stimulus difficulty (modulation depth), $m$ the midpoint, $w$ the width of the interval over which $F(x ; m, w)$ rises from $\delta$ to $1-\delta, \lambda$ the lapse rate, and $\gamma$ the FA rate. Both $m$ and $w$ were unconstrained, and $\delta$ was fixed at 0.1 (the default in psignifit). The prior distribution for the FA rate $(\gamma)$ was defined as a beta distribution with the parameters $\alpha=N_{F A}+1$ and $\beta=N_{C R}+1$ such that the mode of the distribution was fixed at the session's observed FA rate. The prior distribution for the lapse rate $(\lambda)$ was defined as a beta distribution with a mode of $0.05(\alpha=1.5 ; \beta=12)$. Similar values were used in a previous study from our laboratory that examined gerbil frequency modulation depth detection (Buran et al., 2014).

The deviance (a measure that describes the goodness of fit for a model) was calculated for each of our fits (for details, see Wichmann and Hill, 2001a, b; Fründ et al., 2011). We discarded any fit whose deviance exceeded the 95th percentile of the deviances from a bootstrapped sample of 2000 simulated datasets. Valid fitted functions were transformed to the signal detection metric $d^{\prime}$, where $d^{\prime}=Z$ (hit rate) $-Z$ (FA rate) (Green and Swets, 1966). $d^{\prime}$ approaches infinite values when the FA rate $=0$ or the hit rate $=1$. To avoid this scenario, a log-linear correction was applied, such that 0.5 was added to the number of hits, misses, FAs, and CRs before fitting (Hautus, 1995).

Threshold was determined for each of our valid fits and defined as the AM depth at which $d^{\prime}=1$. In two sessions (from the same earplug-reared animal), the performance was so poor that the psychometric function did not reach a $d^{\prime}$ of 1 . In both of these cases, threshold was set to the upper bound for amplitude modulation depth (0 dB re: 100\%).

Statistics. Statistical analyses were performed using JMP 9.0.1 (SAS) on a Mac platform. Unless otherwise stated, all data met assumptions of normality and homogeneity of variance (as assessed by Levene's test). When violations of sphericity were present (as assessed by Mauchley's test), Greenhouse-Geisser corrections were applied (Greenhouse and Geisser, 1959). This correction is responsible for any noninteger degrees of freedom reported here. For ABR analyses, some peaks were not present for all sound levels in all animals. Missing values present an obstacle for 

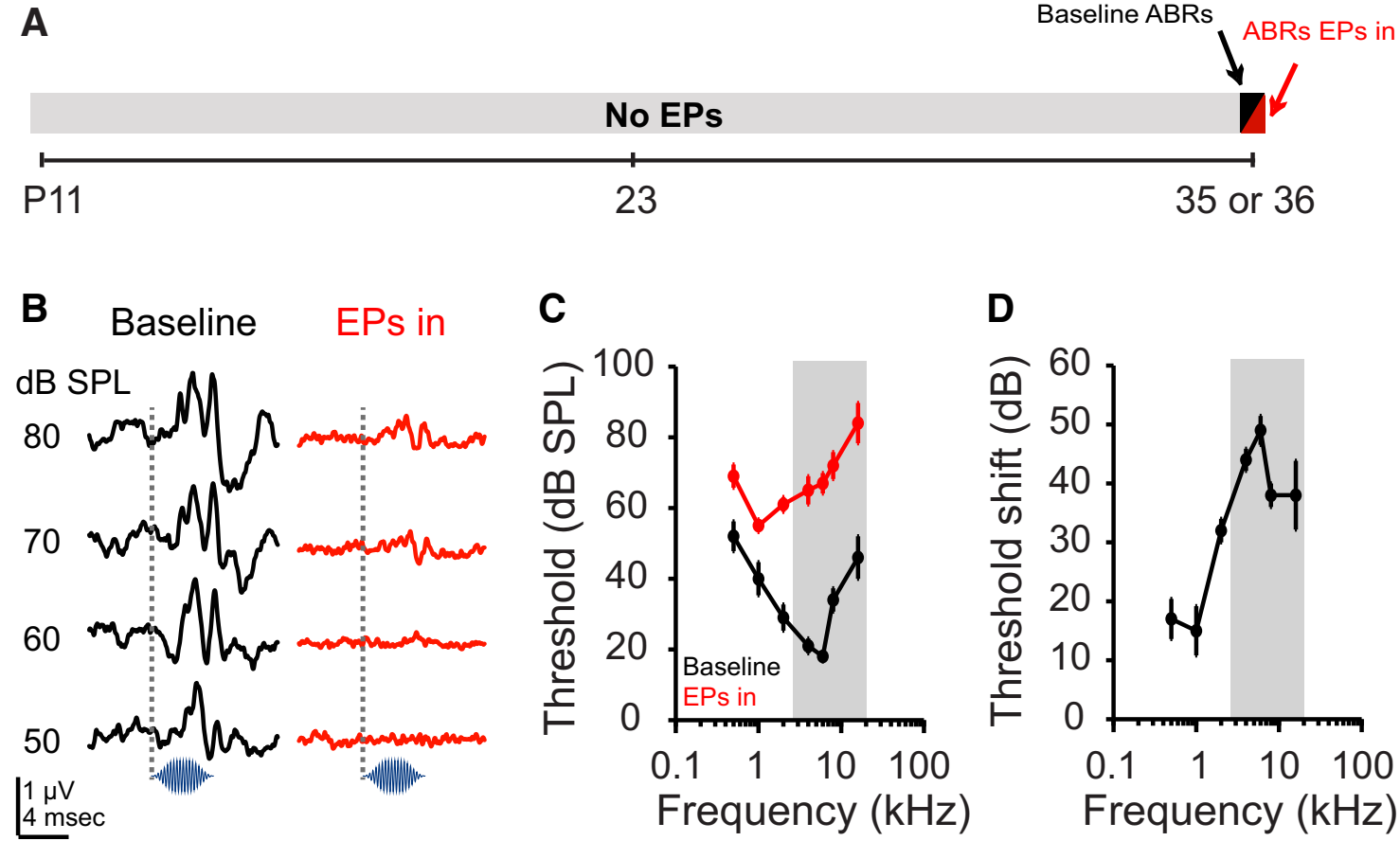

Figure 2. Bilateral earplugs (EPs) induce reliable sound attenuation. $\boldsymbol{A}$, Timeline of experimental manipulations for data shown in $\boldsymbol{B}-\boldsymbol{D}$. Animals were raised with normal auditory input. Immediately (minutes) after the collection of baseline ABRs at either P35 or P36, bilateral EPs were inserted and ABRs were recorded again. Threshold was identified as the lowest sound level to elicit a reliable response. $\boldsymbol{B}$, Representative ABR traces from a single P36 animal before (left) and after (right) acute bilateral EP insertion. Traces were evoked by a 4 kHz pure tone (shown below traces). Dashed line indicates onset. C, Group ABR audiograms before (black) and during (red) acute bilateral EP insertion. Shaded region represents bandwidth of the noise stimulus used in the behavioral detection task. $\boldsymbol{D}$, Group threshold shifts as a function of frequency. Data are mean $\pm \operatorname{SEM}(n=5)$.

performing a repeated-measures ANOVA; therefore, we initially analyzed our data twice: once including all animals (discarding any sound levels with missing values) and again including all sound levels (discarding any animals with missing values). Both methods yielded qualitatively similar results; therefore, we report only the results of the latter analysis here. In instances of multiple comparisons, $p$ values were corrected using the Holm-Bonferroni method.

\section{Results}

\section{Characterizing earplug-induced attenuation}

To measure the attenuation induced by earplugs as a function of frequency, ABRs were recorded in five animals immediately before and during acute earplug insertion. These animals were between P35 and P36 at the time of ABR recording (Fig. 2A) and were not tested in the behavioral paradigm described below. Representative $A B R$ traces from a single animal before and during earplug insertion demonstrate marked sound attenuation (Fig. $2 B$ ). As shown in Figure 2C, earplugs elevated ABR thresholds across all frequencies tested. A two-way repeated-measures ANOVA revealed significant effects of frequency $\left(F_{(2.97,11.89)}=\right.$ 5.82, $p=0.01)$ and earplug $\left(F_{(1,4)}=994.57, p<0.0001\right)$. A significant interaction between the two variables $\left(F_{(1.98,7.92)}=\right.$ $111.60, p<0.0001)$ resulted in greater attenuation for higher frequencies, with average threshold shifts ranging from $15 \mathrm{~dB}$ at 1 $\mathrm{kHz}$ to $49 \mathrm{~dB}$ at $6 \mathrm{kHz}$ (Fig. 2D).

\section{AM detection is vulnerable to auditory deprivation during a critical period}

To determine whether the maturation of AM depth perception was vulnerable to transient developmental deprivation, animals were either reared with normal hearing $(n=13)$ or with bilateral earplugs from P11 (the day of ear canal opening) to P23 $(n=16)$. At P38, 15 days after earplug removal, animals were tested on the
AM depth detection task (Fig. 3A). Representative data from one earplug-reared animal and one normally reared littermate illustrate that P11-P23 deprivation decreases the sensitivity of psychometric functions at P38 (Fig. 3A). On average, earplug rearing elevated $\mathrm{AM}$ detection thresholds by $2.3 \mathrm{~dB}\left(t_{(27)}=2.25, p=\right.$ 0.03; Fig. $3 A$ ).

This finding could reflect either a specific developmental critical period during which the maturation of AM detection is vulnerable to auditory deprivation or could reflect a vulnerability to hearing loss that does not depend on age. To distinguish between these possibilities, a separate group of animals was reared either with normal auditory input $(n=11)$ or with earplugs from P23P35 $(n=12)$ and tested on the AM detection task at P50 (Fig. 3B). Thus, these animals experienced the same duration of deprivation (12 d) and the same duration of restored sensory input (15d) as those in the first experimental group. As shown in Figure $3 B$, P23-P35 deprivation did not affect subsequent AM depth perception $\left(t_{(21)}=0.10, p=0.92\right)$. Together, these findings suggest that P11-P23 encompasses a critical period during which AM perceptual development is vulnerable to transient sound attenuation.

The AM detection impairment induced by P11-P23 earplugging may reflect a permanent deficit or one that resolves with additional maturation. To address this issue, a separate, naive group of animals was reared either with normal auditory input $(n=12)$ or with earplugs from P11-P23 $(n=12)$ and tested on the AM depth detection task between P100 and P119 (sexual maturation occurs at $\sim$ P90; Fig. $3 C$ ). On average, adult animals raised with earplugs between P11 and P23 displayed normal AM detection thresholds $\left(t_{(22)}=1.21, p=0.24\right.$; Fig. $\left.3 C\right)$, but 2 of the 12 animals displayed AM thresholds 2.4 and $4.0 \mathrm{~dB}$ above the normative adult range. Thus, critical period deprivation induced 

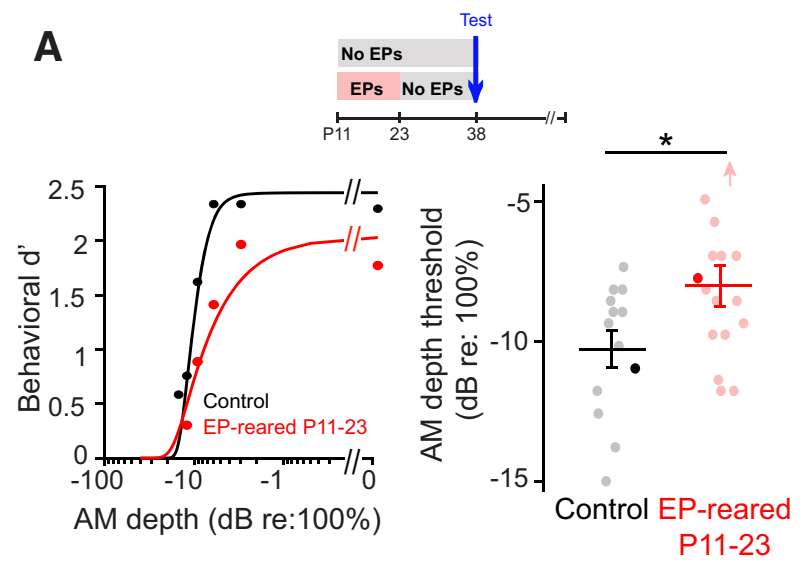
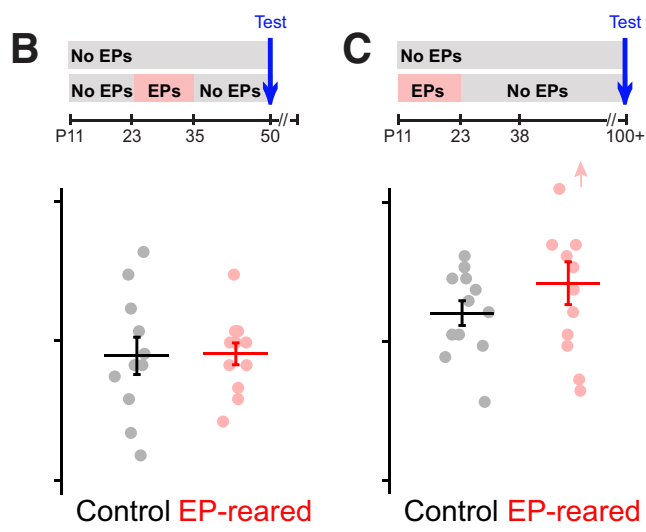

P23-35

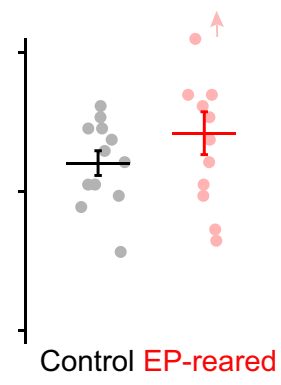

P11-23

Figure 3. AM detection is sensitive to auditory deprivation between P11 and P23. A, Top, Experimental timeline for data in $\boldsymbol{A}$. Animals were raised with either normal auditory input (controls) or earplugs (EPs) from P11 to P23. All animals were tested at P38 (15 d after removal of EPs from the experimental group). Bottom left, Representative psychometric functions from a juvenile animal reared with bilateral EPs from P11 to P23 (red) and a normally reared littermate (black). Threshold was defined as the depth at which $d^{\prime}=1$. Bottom right, Mean \pm SEM AM detection thresholds for juveniles reared with P11-P23 EPs and normally reared littermates. Circles represent thresholds for individual animals in each group. Dark circles represent thresholds obtained from the psychometric functions depicted at left. ${ }^{*} p<0.05$. B. Top, Experimental timeline for data in $\boldsymbol{B}$. Animals were raised with either normal auditory input (controls) or EPs from P23 to P35. All animals were tested at P50 ( $15 \mathrm{~d}$ after removal of EPs from the experimental group). Bottom, Mean \pm SEM. AM detection thresholds for animals reared with P23-P35 EPs and normally reared littermates. C, Top, Experimental timeline for data in C. Animals were raised with either normal auditory input (controls) or EPs from P11 to P23. All animals were tested on or after P100, which is after sexual maturity ( P90). Data are mean \pm SEM AM detection thresholds for adult animals reared with P11-P23 EPs and normally reared littermates.

a perceptual deficit that resolved by adulthood for most, but not all, animals tested.

In some animals, the earplugs became dislodged or were lost as the ear canal widened during development. To quantify this, we calculated earplug scores (see Materials and Methods), which ranged from 1.1 (indicating an average of approximately one earplug in place, each day) to 2 (indicating perfect plugging) (mean $\pm \mathrm{SD}=1.5 \pm 0.2, n=40$ ). To determine whether earplug stability impacted the behavioral results presented above, we asked whether there was a correlation between each individual animal's earplug score and its initial AM depth threshold. No correlations were found for animals raised with earplugs between P11 and P23 and tested at P38 (Pearson's $r=0.17, p=0.54, n=$ 16), animals raised with earplugs between $\mathrm{P} 23$ and $\mathrm{P} 35$ and tested at P50 $(r=0.39, p=0.20, n=12)$, or animals raised with earplugs between P11 and P23 and tested as adults $(r=0.22, p=$ $0.50, n=12$ ). These findings suggest that the stability of the earplugs does not account for the behavioral variability across animals.

\section{Critical period deprivation affects perceptual learning in some animals}

The findings presented above revealed that critical period sound attenuation elevated juvenile naive AM detection thresholds. However, AM sensitivity can improve with training, raising the possibility that transient deprivation could also affect perceptual learning (Sarro and Sanes, 2010, 2011; Fitzgerald and Wright, 2011; Sarro et al., 2011). To explore this issue, juvenile animals raised with earplugs from P11-P23 ( $n=9$ of the original 16), and normally reared littermates ( $n=7$ of the original 13 ) were tested on the AM depth detection task for 7 consecutive days (Fig. 4A). As shown in Figure $4 B$, performance improved with repeated testing for both groups. An ANCOVA revealed a significant effect of task experience $\left(F_{(1,108)}=27.93, p<0.0001\right)$, such that AM detection thresholds decreased by $0.88 \mathrm{~dB}$ (re: $100 \%$ depth) per test day. No significant interaction between test day and earplug rearing was observed $\left(F_{(1,108)}=0.71, p=0.40\right)$; however, there was a significant effect of earplug rearing alone $\left(F_{(1,108)}=14.21\right.$, $p=0.0003)$. On average, AM detection thresholds of earplug- reared animals were $2.5 \mathrm{~dB}$ higher than their normally reared littermates across all testing days. A closer look at the distribution of final AM thresholds reveals that $7 \mathrm{~d}$ of repeated testing failed to restore normal performance in 5 of 9 of earplug reared animals. Here, note that we define "normal" as a function of both age and experience.

These results indicate that, at a group level, critical period deprivation elevated AM detection thresholds but did not impair the overall rate of perceptual learning. Because the adult data (Fig. 3C) suggested between-subject variability in the recovery of AM detection, we examined the effect of repeated testing on a case-by-case basis. For each animal, AM detection thresholds were plotted as a function of testing day and were fit with a linear regression. Although each subject improved over the 7 consecutive testing days, they did so at different rates, particularly those raised with bilateral earplugs (Fig. $4 C$ ). To determine whether there was a relationship between the rate of improvement and naive AM sensitivity, we plotted the slope of each regression line as a function of the initial AM threshold (Fig. 4D). Normally reared animals with low (good) starting thresholds improved more slowly than animals with poorer initial performance (Pearson's $r=-0.81, p=0.03)$. No such correlation was observed for animals raised with transient deprivation (Pearson's $r=-0.30$, $p=0.43$ ). Indeed, the 6 earplug-reared animals (Fig. $4 D$, red circles) that fall outside the error margins of the control fit indicate that the majority of earplug-reared animals improved either more slowly ( 4 of 9 ) or more quickly ( 2 of 9 ) than would be expected from their naive performance. These findings suggest that critical period deprivation affects perceptual learning in a subject-specific manner.

\section{Elevated AM thresholds are not explained by differences in training or task-specific factors}

Elevated juvenile AM thresholds induced by P11-P23 deprivation could reflect a perceptual deficit or could instead result from differences in procedural training. If earplug-reared animals were slower to learn the task than their normally reared littermates, or did not learn the task as well, then performance may have been poorer. To address this issue, we examined behavioral perfor- 

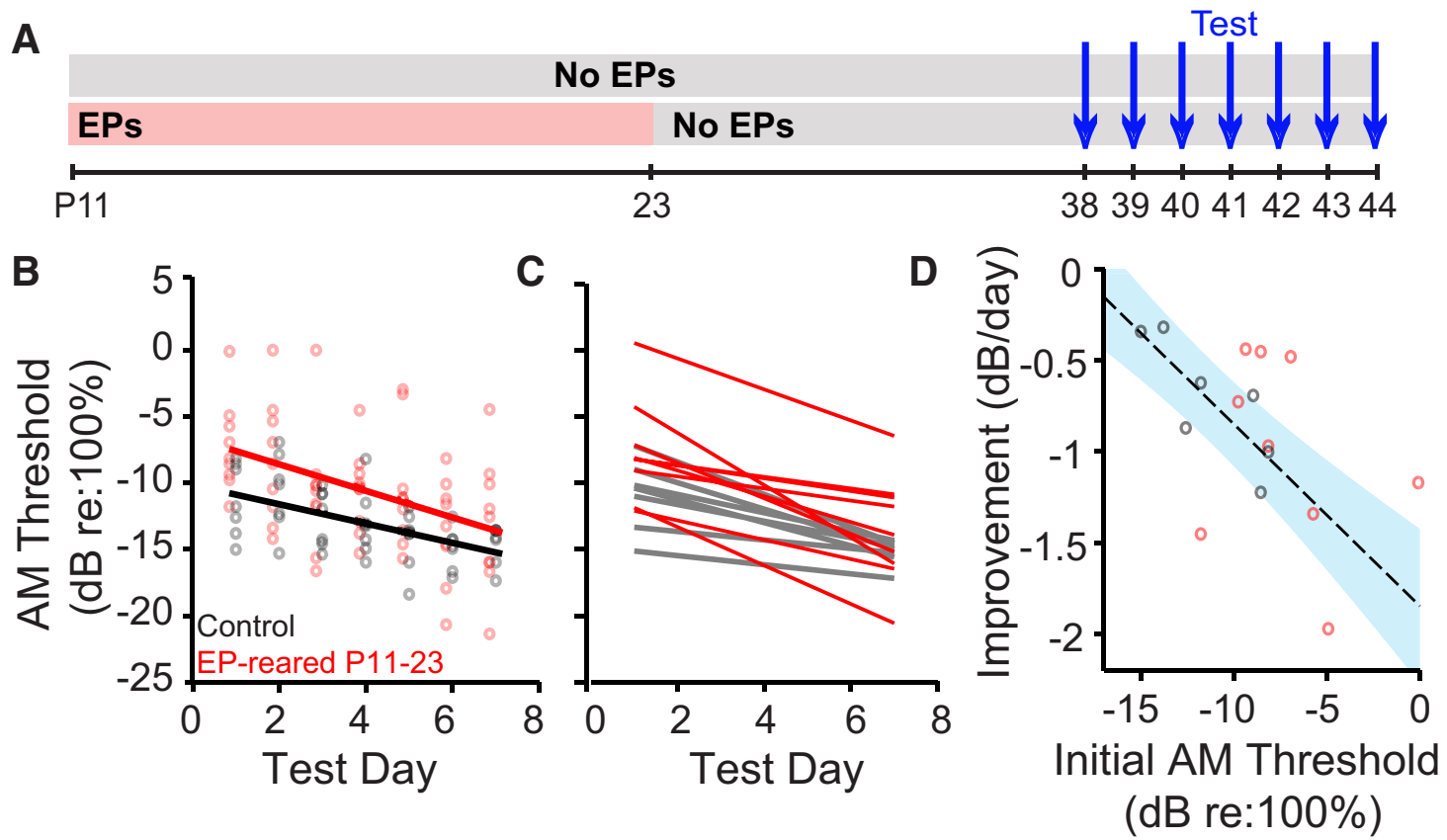

Figure 4. P11-P23 auditory deprivation affects perceptual learning in a subject-specific manner. $A$, Experimental timeline for data in $\boldsymbol{B}-\boldsymbol{D}$. Animals were raised with either normal auditory input or earplugs (EPs) from P11 to P23. All animals were tested from P38 (15 d after removal of EPs from the experimental group) to P44. B, AM detection thresholds of both P11-P23 EP-reared animals (red) and normally reared littermates (black) decline over the course of 7 consecutive test days. Regression lines indicate ANCOVA model fits. The lines do not have significantly different slopes, indicating that, on average, both groups display the same rate of perceptual improvement. The lines do have significantly different intercepts, such that EP rearing results in a consistent AM detection deficit across test days. $\boldsymbol{C}$, Linear regressions obtained by fitting improvement functions for individual animals. EP-reared animals (red) display marked between-subject variability in the rate of threshold improvement. D, Threshold improvement (i.e., the slope of the linear fits in C) as a function of initial (naive) AM detection threshold. A significant negative correlation is observed for control animals (dashed line). Shaded blue region represents the SD of the regression's prediction error. No correlation was observed for EP-reared animals (red circles). The majority of EP-reared animals ( 6 of 9 ) fall outside the error margins for the control regression.

A

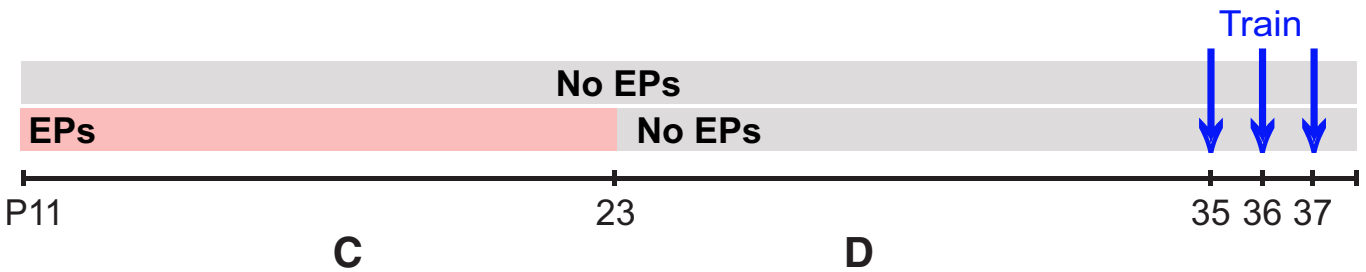

B

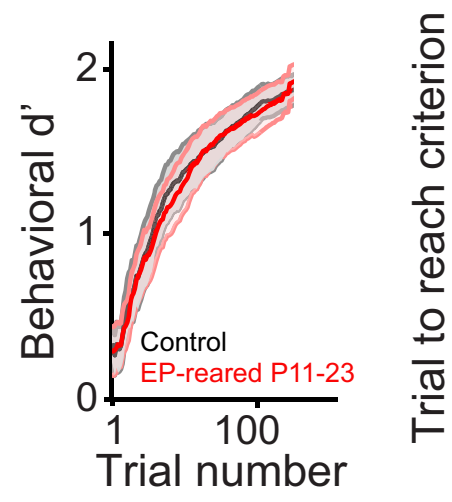

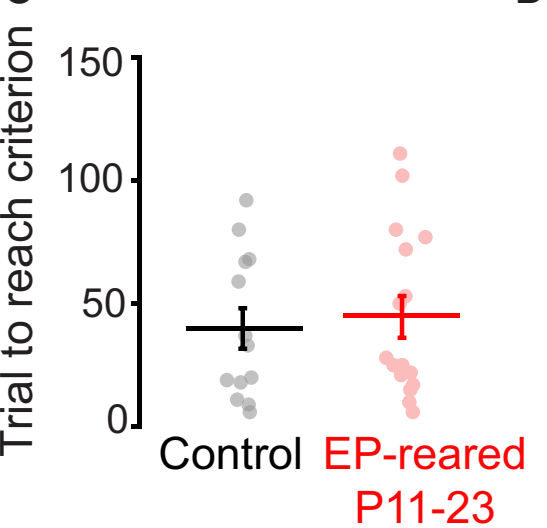

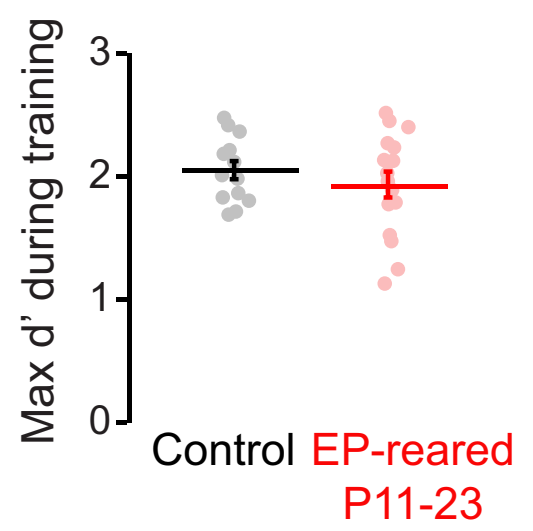

Figure 5. Elevated AM detection thresholds induced by $P 11-P 23$ auditory deprivation cannot be explained by inadequate procedural learning. $\boldsymbol{A}$, Experimental timeline for data in $\boldsymbol{B}-\boldsymbol{D}$. Animals were raised with either normal auditory input or bilateral earplugs (EPs) from P11 to P23. All animals were trained from P35 to P37 (12-14 d after removal of EPs from experimental group). $\boldsymbol{B}$, During training, cumulative $d^{\prime}$ values of animals reared with P11-P23 EPs (red) and normally reared littermates (black) increase at the same rate as a function of trial number. $C$, Both groups required a similar number of trials to reach and maintain a $d^{\prime}$ of 1 (criterion) during training. $D$, The maximum $d^{\prime}$ value achieved during training was similar in both groups. Data are mean \pm SEM.

mance during the 3 training days leading up to the AM test session at P38 (Fig. 5A). As shown in Figure 5B, both groups displayed similar rates of improvement in their sensitivity $\left(d^{\prime}\right)$ to the training stimulus (100\% depth). As expected, a two-way mixed-model ANOVA revealed a significant effect of trial number on cumulative $d^{\prime}\left(F_{(92,2484)}=102.7, p<0.0001\right)$, but no effect of earplug experience $\left(F_{(1,27)}=0.0221, p=0.88\right)$, and no interaction between the two variables $\left(F_{(92,2484)}=0.2193, p=\right.$ 
A

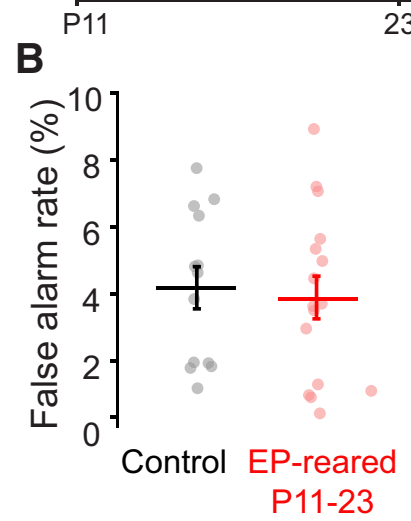

C

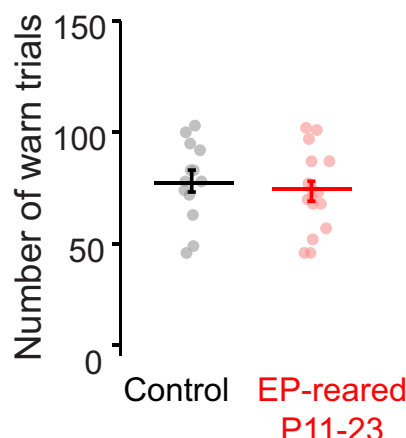

Figure 6. Elevated AM detection thresholds induced by P11-P23 auditory deprivation cannot be explained by task-specific factors. $\boldsymbol{A}$, Experimental timeline for data in $\boldsymbol{B}, \boldsymbol{C}$. Animals were raised with either normal auditory input or earplugs (EPs) from P11 to P23. All animals were tested at P38 (15 d after removal of EPs from the experimental group). $B$, Mean \pm SEM FA rates for juvenile animals reared with P11-P23 EPs and normally reared littermates. C, Mean \pm SEM; number of warn trials performed during a single test session. All data were collected at P38.

1.00). Animals from both groups required a similar number of trials to reach a $d^{\prime}$ of $1\left(t_{(27)}=0.37, p=0.72\right.$; data were logtransformed before testing because they were non-normally distributed; Fig. $5 C$ ). Furthermore, earplug rearing had no effect on the maximum $d^{\prime}$ value achieved during training $\left(t_{(27)}=\right.$ $-0.87, p=0.39$; Fig. $5 D)$, indicating that both groups were similarly proficient at the task before they were advanced to the psychometric testing regimen.

Elevated AM thresholds could also be attributed to several task-specific factors, such as confidence and motivation. To address these issues, we examined two metrics (Fig. 6A). First, FA rate was assessed because it can be influenced by experimental variables unrelated to perception, including the difficulty of the stimulus set and the shock level. All animals maintained relatively low $(<10 \%)$ FA rates (Fig. $6 B$ ), and no significant group effect was observed $\left(t_{(27)}=-0.32, p=0.75\right)$. Second, we examined the subjects' participation in the task. Within a given session, animals were required to complete at least 8 trials per depth before we adjusted any stimulus values. Thus, between-group differences in trial number could result in systematic differences in task difficulty. As illustrated in Figure 6C, P11-P23 earplug-reared and normally reared littermates performed a similar number of Go trials $\left(t_{(27)}=-0.69, p=0.50\right)$. Furthermore, AM detection thresholds did not significantly correlate with the number of Go trials completed (Pearson's $r=-0.21, p=0.28$; data not shown), indicating that motivational differences between the groups are unlikely to account for the AM detection deficits. Collectively, these findings suggest that task-specific factors are unlikely to explain the poor AM detection thresholds exhibited by earplugreared animals.

\section{Elevated AM thresholds are not explained by impaired peripheral function}

It is possible that P11-P23 earplug-reared juveniles display poorer AM detection because their peripheral transduction system was damaged or compromised by the experimental manipulation, resulting in decreased audibility. To address this issue, we recorded ABRs from animals raised with earplugs from P11-
P23 ( $n=7$ of the original 16) and normally reared littermates ( $n=6$ of the original 13). These animals were tested on the AM depth detection task at P38 and were thus included in the behavioral data presented in Figures 3, 5, and 6. However, these animals were not tested repeatedly, and thus did not contribute to the data in Figure 4. ABRs were recorded shortly (1-72 h) after obtaining psychometric functions at P38 (Fig. 7A). As illustrated in Figure $7 B$, representative $A B R$ traces from one earplug-reared animal and one normally reared littermate suggest that earplug removal allowed audibility to return to control levels. ABR audiograms from the two groups did not differ from one another (Fig. 7C). A two-way mixed-model ANOVA revealed a significant effect of frequency $\left(F_{(6,60)}=46.82, p<0.0001\right)$, but no effect of earplug rearing $\left(F_{(1,10)}=0.12, p=0.73\right)$ nor an interaction between the two variables $\left(F_{(6,60)}=0.79, p=0.58\right)$. To determine whether peripheral hearing status predicted behavioral performance, we averaged $\mathrm{ABR}$ thresholds across 4, 6, 8, and $16 \mathrm{kHz}$ (the four audiogram frequencies that fell within the range of our noise stimulus bandwidth) for each animal. As shown in Figure $7 D$, ABR thresholds did not significantly correlate with AM detection thresholds (Pearson's $r=0.19, p=0.55$ ). Together, these results indicate that the transient earplug-induced impairment of AM detection thresholds could not be explained by inadequate peripheral sensitivity.

Recent findings suggest that the selective loss of high-threshold auditory nerve fibers may negatively impact suprathreshold envelope coding and perception, even in the absence of reduced peripheral sensitivity (Bharadwaj et al., 2014). Thus, if subtle suprathreshold deficits in cochlear function were present in earplug-reared animals, then these deficits could have contributed to the impairment in AM detection. We explored this possibility using two different approaches. First, ABR peak latencies and amplitudes (evoked by $4 \mathrm{kHz}$ pure tones) were examined as a function of sound level. If the earplug manipulation induced cochlear damage, then animals should have displayed shallower growth functions (i.e., reduced ABR amplitudes and longer ABR latencies at medium to high sound levels). As illustrated in Figure $7 E-G$, a two-way mixed-model ANOVA revealed that ABR peak amplitudes grew larger as the sound level increased (wave i: $F_{(6,18)}=6.65, p<0.001$; wave ii/iii: $F_{(1.21,9.71)}=14.18, p<$ 0.0001 ; wave iv: $\left.F_{(5,40)}=10.62, p<0.0001\right)$, but there was no effect of earplug rearing (wave i: $F_{(1,3)}=5.00, p=0.11$; wave ii/iii: $F_{(1,8)}=0.97, p=0.35$; wave iv: $\left.F_{(1,8)}=0.90, p=0.37\right)$ nor a level-condition interaction (wave i: $F_{(6,18)}=1.65, p=0.19$; wave ii/iii: $F_{(1.21,9.71)}=0.68, p=0.46$; wave iv: $\left.F_{(5,40)}=1.45, p=0.23\right)$. Similarly, Figure $7 H-J$ reveals that ABR peak latencies decreased with increasing stimulus intensity (wave i: $F_{(6,18)}=7.24, p<$ 0.001; wave ii/iii: $F_{(7,70)}=137.73, p<0.0001$; wave iv: $F_{(7,49)}=$ $19.29, p<0.0001$ ) but were not affected by earplug rearing (wave i: $F_{(1,3)}=0.21, p=0.67$; wave ii/iii: $F_{(1,10)}=2.14, p=0.17$; wave iv: $\left.F_{(1,7)}=0.77, p=0.41\right)$ nor by an interaction between the two variables (wave i: $F_{(6,18)}=1.09, p=0.41$; wave ii/iii: $F_{(7,70)}=1.81$, $p=0.10$; wave iv: $\left.F_{(7,49)}=1.14, p=0.36\right)$. There was no significant correlation between ABR peak amplitudes or latencies with behavioral AM detection thresholds within individual animals (all Holm-Bonferroni corrected $p>0.05$; data not shown).

Finally, to determine whether the earplug manipulation disrupted the cochlear active process, we assessed frequency selectivity. Forward masking tuning curves from the two experimental groups did not differ significantly from one another (Fig. $7 \mathrm{~K}-\mathrm{L}$ ). As illustrated in Figure $7 M$, earplug rearing had no significant effect on the sharpness of tuning $\left(Q_{10}\right)$ at $4 \mathrm{kHz}\left(t_{(1,8)}=0.58, p=\right.$ $0.58)$ or at $6 \mathrm{kHz}\left(t_{(1,7)}=1.30, p=0.24\right)$. Together, these findings 
A

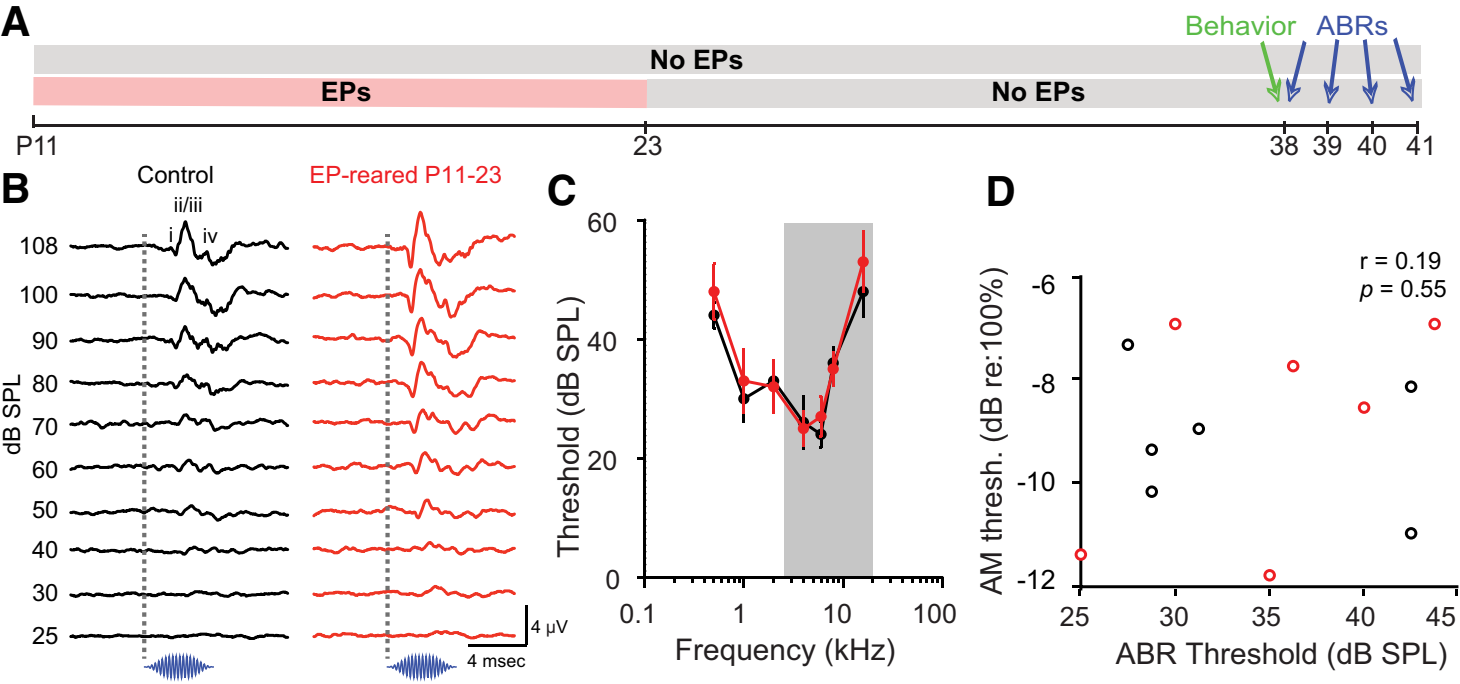

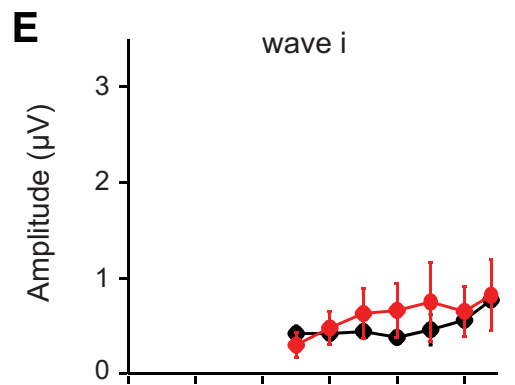

\section{F}

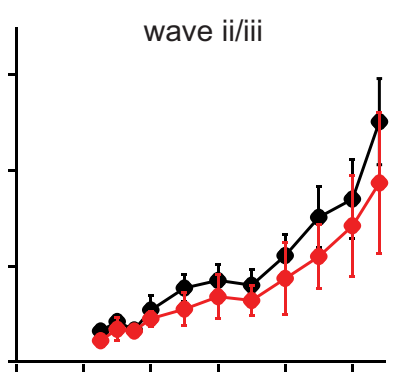

H

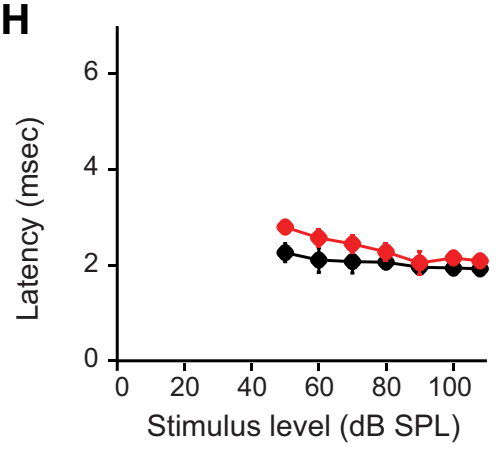

K

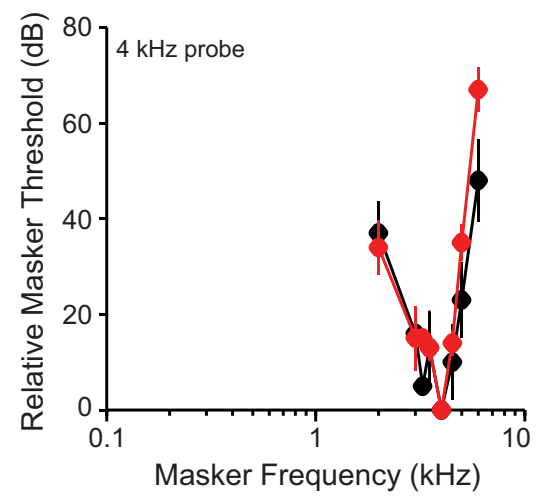

I

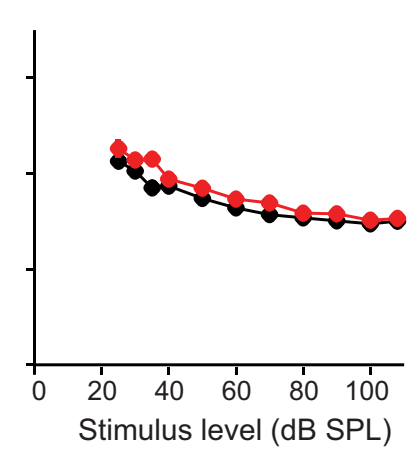

L
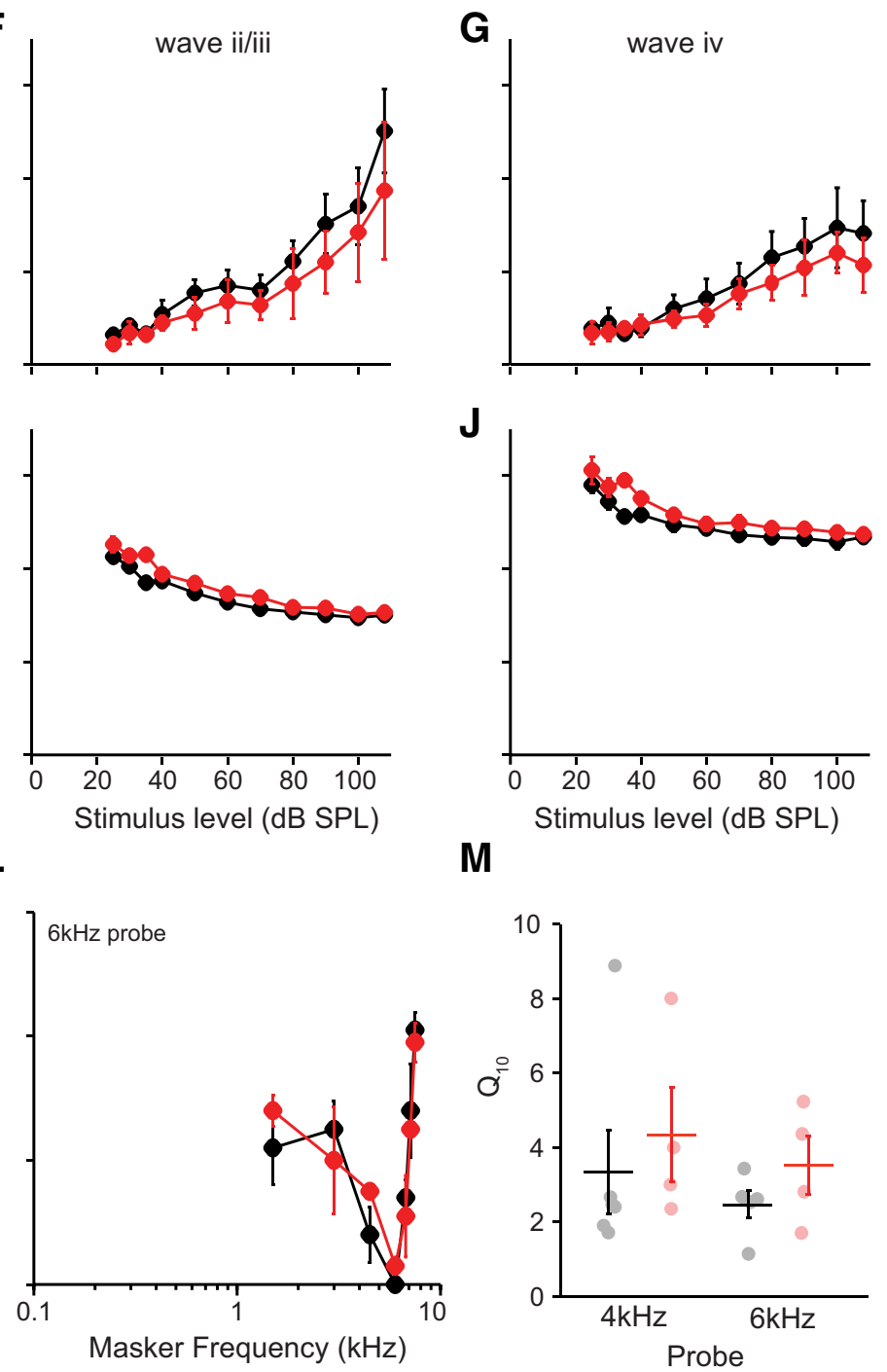

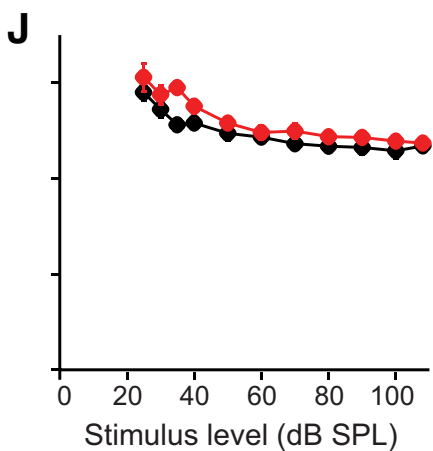

M

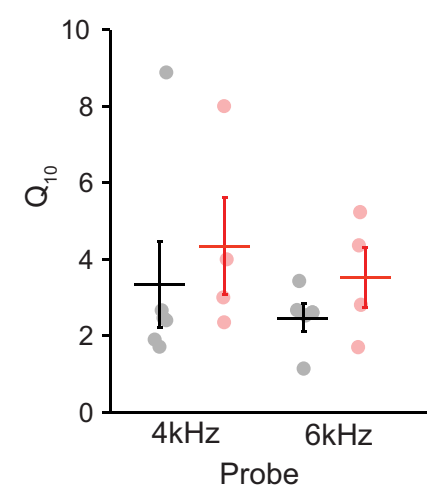

Figure 7. Elevated AM detection thresholds induced by P11-P23 auditory deprivation cannot be explained by impaired peripheral function. $\boldsymbol{A}$, Experimental timeline for data in $\boldsymbol{B}-\boldsymbol{M}$. Animals were raised with either normal auditory input or bilateral earplugs (EPs) from P11 to P23. Behavioral data were collected at $\mathrm{P} 38$ from all animals (15 d after removal of EPs from experimental group). ABRs were recorded following behavior (P38-P41). B, Representative ABR traces from an animal reared with P11-P23 EPs and a normally reared littermate. Traces were evoked by a $4 \mathrm{kHz}$ pure tone. Dashed line indicates onset. Waves labeled as in Burkard et al. (1993). C, Mean \pm SEM ABR audiograms from animals raised with P11-P23 EPs and normally reared littermates. Data were collected between P38 and P41. D, Individual behavioral AM detection thresholds ( $y$-axis) do not correlate with ABR thresholds ( $x$-axis). Here, ABR thresholds represent the average of 4, 6, 8, and 16 kHz thresholds (the frequencies within the region of the broadband noise used in the behavioral experiments; see shading in $\boldsymbol{B})$. $\boldsymbol{E}-\boldsymbol{G}$, Mean \pm SEM ABR wave $\mathrm{i}(\boldsymbol{E})$, wave ii/iii $(\boldsymbol{F})$, and wave iv $(\boldsymbol{G})$ amplitudes plotted as a function of sound level. $\boldsymbol{H}-\boldsymbol{J}$, Mean \pm SEM ABR wave i $(\boldsymbol{H})$, wave ii/iii $(\boldsymbol{I})$, and wave iv $(\boldsymbol{J})$ latencies plotted as a function (Figure legend continues.) 
suggest that elevated AM detection thresholds cannot be adequately explained by deficits in peripheral function.

\section{Discussion}

Developmental periods of enhanced experience-dependent plasticity have shaped our understanding of how the early auditory environment impacts perceptual abilities throughout life, particularly in the contexts of vocal learning (Marler and Tamura, 1964; Werker et al., 1981; Kuhl et al., 1992), musical training (Penhune, 2011), and auditory deprivation (Sanes and Bao, 2009). In this study, we found that the developmental critical periods for certain cortical properties, including evoked firing rates (Mowery et al., 2014), are closely aligned with a critical period for perception. Specifically, sensitivity to AM, a temporal cue that supports vocal communication, is vulnerable to transient auditory deprivation during a very brief period of development, from P11 to 23, but not thereafter. Animals subjected to sound attenuation during this time window demonstrated pronounced between-subject variability in the rate and extent of perceptual recovery. Together, these findings suggest that central disruptions associated with transient developmental deprivation give rise to lasting perturbations in sound encoding and nonsensory mechanisms that impair the ability to learn about AM features. Our results may partially account for the speech and language delays associated with transient childhood hearing loss.

\section{Potential mechanisms for perceptual impairment}

Although AM depth sensitivity is not strongly dependent on stimulus level (Viemeister, 1979), it is possible that P11-P23 earplug-reared juveniles are poor at AM detection because their peripheral transduction system was damaged or compromised by the experimental manipulation, resulting in decreased audibility. Contrary to this idea, our ABR experiments revealed that cochlear function remained intact after earplug rearing (Fig. 7). These findings suggest that critical period sound attenuation gives rise to central perturbations that outlast the period of deprivation, and these disruptions account for the behavioral deficits we report here.

Several previous findings support the notion that central auditory encoding is sensitive to critical period deprivation, yet they focus largely on monaural manipulations and their effect on binaural processing. In a series of important experiments, Knudsen and colleagues found that animals that are unilaterally earplugged before the age of $\mathrm{P} 60$ adapt to the plug both behaviorally and neurally, whereas animals that are plugged after P60 show no evidence of adaptation (Knudsen et al., 1982, 1984b; Knudsen, 1983, 1985; Mogdans and Knudsen, 1992, 1993, 1994). Complementary results have been obtained in several species, leading to the conclusion that the central mechanisms underlying binaural perception depend on early auditory experience (Clements and Kelly, 1978; Moore and Irvine, 1981; King et al., 1988; Wilmington et al., 1994; Moore et al., 1999; King et al., 2000; Kacelnik et al., 2006; Popescu and Polley, 2010; Keating et al., 2013, 2015; Polley et al., 2013; Tomlin and Rance, 2014). These findings are consistent with a broad range of developmental plasticity studies that report robust consequences of "competition" experiments in which a subset of sensory afferents are deprived of stimulation

$\leftarrow$

(Figure legend continued.) of sound level. $\boldsymbol{K}-\boldsymbol{L}$, Mean \pm SEM ABR forward masking tuning curves for a $4 \mathrm{kHz}$ probe $(\boldsymbol{K})$ and a $6 \mathrm{kHz}$ probe $(\boldsymbol{L}) . \boldsymbol{K}, \boldsymbol{L}$, The relative masker threshold $(y$-axis) is normalized to the level at the tip of the curve. For details, see Materials and Methods. $\boldsymbol{M}$, Individual (circles) and mean \pm SEM (bars) $Q_{10}$ values for $4 \mathrm{kHz}$ and $6 \mathrm{kHz}$ curves. (e.g., close one eye, plug one ear, trim one whisker). However, the neural and behavioral effects of system-wide deprivation (e.g., close both eyes, plug both ears, trim all whiskers) are not axiomatic. For example, the literature clearly indicates that the effects of bilateral visual deprivation are quite distinct from those due to unilateral deprivation (Wiesel and Hubel, 1965; Sherman and Spear, 1982). Therefore, a primary motivation of the present study was to understand whether auditory deprivation disrupts behavioral percepts other than sound localization.

Acoustic experience clearly influences the development of CNS properties that do not depend on binaural processing. For example, rearing animals in a diminished or abnormal acoustic environment disrupts cortical tonotopic organization (de Villers-Sidani et al., 2007; Barkat et al., 2011) and spectrotemporal processing (Aizawa and Eggermont, 2006; Razak et al., 2008; Insanally et al., 2009; Rosen et al., 2012). Furthermore, a recent study from our laboratory identified several discrete critical periods during which certain cortical cellular and synaptic properties are vulnerable to transient earplugging (Mowery et al., 2014). Here, we report that an identical manipulation perturbed the perception of AM, but only if the manipulation occurred between P11 and P23 (Fig. 3). Thus, we have identified here a critical period of gerbil development during which both sound perception and cortical cellular properties, including evoked activity (Mowery et al., 2014; their Fig. 6H), are vulnerable to transient auditory deprivation. Together with earlier work demonstrating that animals reared with permanent conductive hearing loss display reduced AM-evoked firing rates (Rosen et al., 2012), these findings lead to the hypothesis that a brief bout of bilateral deprivation during a developmental critical period disrupts cortical excitability, which in turn generates subsequent deficits in AM encoding and perception.

\section{Comparison with human literature}

Although certain factors make it difficult to directly place our results within a human context (e.g., hearing onset is prenatal in humans, but postnatal in gerbils), it is of interest to compare our findings with the clinical literature. Here, we report that gerbil AM depth perception is most vulnerable to auditory deprivation between postnatal day 11 (the age of hearing onset) and postnatal day 23 ( $\sim 10$ weeks before sexual maturity). By contrast, peak vulnerability in humans seems to occur between infancy and late toddlerhood. The best evidence for a human auditory critical period comes from profoundly deaf children who receive cochlear implants. Children implanted before 2 years display steeper rates of improvement on receptive and expressive language tests, compared with those implanted after 36 months (Niparko et al., 2010). These language deficits persist for at least 6 years after implantation for late-implanted children (Tobey et al., 2013). Similarly, infants with mild to moderate hearing loss who receive hearing aid amplification by 3 months of age, and audiovisual intervention by age 6 months, later score within normal limits on speech and language assessments and outperform a similar cohort of children that were identified as hearingimpaired after 12 months of age (Fulcher et al., 2012). These findings suggest that our P11-P23 gerbil critical period is broadly comparable to $0-2$ years in humans. It is important to note, however, that a more severe hearing loss manipulation and/or a more difficult behavioral task may reveal vulnerabilities beyond the P11-P23 range reported here. 


\section{Recovery of perceptual skills is subject-specific}

When tested as adults, there was no significant difference in average AM sensitivity between a group of animals raised with P11P23 earplugs versus a group of normally reared littermates (Fig. $3 C$ ). This result is consistent with previous findings suggesting that juvenile perceptual deficits can resolve with additional maturation. For example, barn owls reared with a unilateral earplug demonstrate impaired sound localization immediately following the removal of the plug, but performance can improve to normal levels over time (Knudsen et al., 1982, 1984a, b). Similarly, children with a history of otitis media display deficits in binaural hearing (Moore et al., 1991; Pillsbury et al., 1991; Hall et al., 1995; Hogan et al., 1996; Hall et al., 1998) and speech processing (Jerger and Johnson, 1988; Gravel and Wallace, 1992; Gravel et al., 1996; Hall et al., 2003) that gradually recover after normal peripheral audibility is restored. However, some individuals with a history of hearing loss continue to perform poorly on perceptual tasks, long after the average group differences are statistically insignificant (Wilmington et al., 1994; Hall et al., 1995). Our results mirror this human finding: some earplug-reared gerbils (2 of 12) displayed elevated AM thresholds $>3$ months after earplug removal (Fig. 3C).

The effects of early deprivation may extend beyond a sensory deficit. When earplug-reared juvenile animals were tested on the AM detection task for 7 consecutive days, the rate of improvement was quite variable. Five of nine earplug-reared subjects performed more poorly than the worst control animal after 7 days of testing, and four of these subjects progressed more slowly than would be predicted from their initial AM depth thresholds (Fig. 4). This finding is consistent with the human behavioral literature. Developmental hearing loss can impair cognitive abilities, such as learning (Pittman et al., 2005; Conway et al., 2011) and memory (Burkholder and Pisoni, 2003; Pisoni and Cleary, 2003; Pisoni et al., 2011; Beer et al., 2014; Kronenberger et al., 2014). Thus, in some individuals, experience-dependent changes in CNS properties may impact nonsensory processing. Together, these results suggest that nonsensory factors (e.g., decision making, learning, and memory) may contribute to individual differences in perceptual recovery.

In conclusion, experience can directly regulate the anatomical and functional development of CNS regions devoted to sensory processing, particularly during discrete developmental epochs. In principle, these experience-dependent changes could either induce life-long perceptual deficits or create transient impediments that resolve by adulthood. To distinguish between these possibilities, we assessed the effect of transient auditory deprivation on AM detection in immature and mature animals. Our key finding is that even a brief bout of auditory deprivation disrupted juvenile AM detection and affected perceptual learning in a subjectspecific manner. Because the auditory periphery was functionally normal, our results suggest that one or more central loci (e.g., Mowery et al., 2014) are responsible for the behavioral impairments described here.

\section{References}

Achor LJ, Starr A (1980) Auditory brain stem responses in the cat: I. Intracranial and extracranial recordings. Electroencephalogr Clin Neurophysiol 48:154-173. CrossRef Medline

Aizawa N, Eggermont JJ (2006) Effects of noise-induced hearing loss at young age on voice onset time and gap-in-noise representations in adult cat primary auditory cortex. J Assoc Res Otolaryngol 7:71-81. CrossRef Medline

Arlinger S (2003) Negative consequences of uncorrected hearing loss: a review. Int J Audiol 42 [Suppl 2]:S17-S20.
Barkat TR, Polley DB, Hensch TK (2011) A critical period for auditory thalamocortical connectivity. Nat Neurosci 14:1189-1194. CrossRef Medline

Beer J, Kronenberger WG, Castellanos I, Colson BG, Henning SC, Pisoni DB (2014) Executive functioning skills in preschool-age children with cochlear implants. J Speech Lang Hear Res 57:1521-1534. CrossRef Medline

Beitchman JH, Brownlie EB, Inglis A, Wild J, Ferguson B, Schachter D, Lancee W, Wilson B, Mathews R (1996) Seven-year follow-up of speech/language impaired and control children: psychiatric outcome. J Child Psychol Psychiatry 37:961-970. CrossRef Medline

Bharadwaj HM, Verhulst S, Shaheen L, Liberman MC, Shinn-Cunningham BG (2014) Cochlear neuropathy and the coding of supra-threshold sound. Front Syst Neurosci 8:26. CrossRef Medline

Boettcher FA (2002) Presbyacusis and the auditory brainstem response. J Speech Lang Hear Res 45:1249-1261. CrossRef Medline

Brinton B, Fujiki M (1993) Language, social skills, and socioemotional behavior. Lang Speech Hearing Serv Schools 24:194-198. CrossRef

Buchwald JS, Huang C (1975) Far-field acoustic response: origins in the cat. Science 189:382-384. CrossRef Medline

Buran BN, Sarro EC, Manno FA, Kang R, Caras ML, Sanes DH (2014) A sensitive period for the impact of hearing loss on auditory perception. J Neurosci 34:2276-2284. CrossRef Medline

Burkard R, Boettcher F, Voigt H, Mills J (1993) Comments on "Stimulus dependencies of the gerbil brain-stem auditory-evoked response (BAER). I: Effects of click level, rate and polarity" [J Acoust Soc Am 85:2514-2525 (1989)]. J Acoust Soc Am 94:2441-2442. CrossRef Medline

Burkholder RA, Pisoni DB (2003) Speech timing and working memory in profoundly deaf children after cochlear implantation. J Exp Child Psychol 85:63-88. CrossRef Medline

Catts HW, Fey ME, Zhang X, Tomblin JB (1999) Language basis of reading and reading disabilities: evidence from a longitudinal investigation. Sci Stud Reading 3:331-361. CrossRef

Cazals Y, Pelizzone M, Saudan O, Boex C (1994) Low-pass filtering in amplitude modulation detection associated with vowel and consonant identification in subjects with cochlear implants. J Acoust Soc Am 96: 2048-2054. CrossRef Medline

Clements M, Kelly JB (1978) Auditory spatial responses of young guinea pigs (Cavia porcellus) during and after ear blocking. J Comp Physiol Psychol 92:34-44. CrossRef Medline

Conway CM, Pisoni DB, Anaya EM, Karpicke J, Henning SC (2011) Implicit sequence learning in deaf children with cochlear implants. Dev Sci 14:69-82. CrossRef Medline

de Villers-Sidani E, Chang EF, Bao S, Merzenich MM (2007) Critical period window for spectral tuning defined in the primary auditory cortex (A1) in the rat. J Neurosci 27:180-189. CrossRef Medline

Dolan TG, Mills JH, Schmiedt RA (1985) A comparison of brainstem, whole-nerve AP and single-fiber tuning curves in the gerbil: normative data. Hear Res 17:259-266. CrossRef Medline

Erzurumlu RS, Gaspar P (2012) Development and critical period plasticity of the barrel cortex. Eur J Neurosci 35:1540-1553. CrossRef Medline

Espinosa JS, Stryker MP (2012) Development and plasticity of the primary visual cortex. Neuron 75:230-249. CrossRef Medline

Fitzgerald MB, Wright BA (2011) Perceptual learning and generalization resulting from training on an auditory amplitude-modulation detection task. J Acoust Soc Am 129:898-906. CrossRef Medline

Fründ I, Haenel NV, Wichmann FA (2011) Inference for psychometric functions in the presence of nonstationary behavior. J Vis 11:16. CrossRef Medline

Fulcher A, Purcell AA, Baker E, Munro N (2012) Listen up: children with early identified hearing loss achieve age-appropriate speech/language outcomes by 3 years-of-age. Int J Pediatr Otorhinolaryngol 76:17851794. CrossRef Medline

Gertner BL, Rice ML, Hadley PA (1994) Influence of communicative competence on peer preferences in a preschool classroom. J Speech Hear Res 37:913-923. CrossRef Medline

Gravel JS, Wallace IF (1992) Listening and language at 4 years of age: effects of early otitis media. J Speech Lang Hear Res 35:588-595. CrossRef Medline

Gravel JS, Wallace IF, Ruben RJ (1996) Auditory consequences of early mild hearing loss associated with otitis media. Acta Otolaryngol 116:219-221. CrossRef Medline

Gravel JS, Roberts JE, Roush J, Grose J, Besing J, Burchinal M, Neebe E, 
Wallace IF, Zeisel S (2006) Early otitis media with effusion, hearing loss, and auditory processes at school age. Ear Hear 27:353-368. CrossRef Medline

Green DM, Swets JA (1966) Signal detection theory and psychophysics. New York: Wiley.

Greenhouse SW, Geisser S (1959) On methods in the analysis of profile data. Psychometrika 24:95-112. CrossRef

Hall JW 3rd, Grose JH, Pillsbury HC (1995) Long-term effects of chronic otitis media on binaural hearing in children. Arch Otolaryngol Head Neck Surg 121:847-852. CrossRef Medline

Hall JW 3rd, Grose JH, Dev MB, Drake AF, Pillsbury HC (1998) The effect of otitis media with effusion on complex masking tasks in children. Arch Otolaryngol Head Neck Surg 124:892-896. CrossRef Medline

Hall JW, Grose JH, Buss E, Dev MB, Drake AF, Pillsbury HC (2003) The effect of otitis media with effusion on perceptual masking. Arch Otolaryngol Head Neck Surg 129:1056-1062. CrossRef Medline

Hashimoto I, Ishiyama Y, Yoshimoto T, Nemoto S (1981) Brain-stem auditory-evoked potentials recorded directly from human brain-stem and thalamus. Brain 104:841-859. CrossRef Medline

Hautus MJ (1995) Corrections for extreme proportions and their biasing effects on estimated values of $d$. Behav Res Methods Instrum Computers 27:46-51. CrossRef

Heffner HE, Heffner RS (1995) Conditioned avoidance. In: Methods in comparative psychoacoustics (Klmup GM, Dooling RJ, Fay RR, Stebbins WC, eds), pp 79-93. Basel, Switzerland: Springer.

Hogan SC, Moore DR (2003) Impaired binaural hearing in children produced by a threshold level of middle ear disease. J Assoc Res Otolaryngol 4:123-129. CrossRef Medline

Hogan SC, Meyer SE, Moore DR (1996) Binaural unmasking returns to normal in teenagers who had otitis media in infancy. Audiol Neurotol 1:104-111. CrossRef Medline

Insanally MN, Köver H, Kim H, Bao S (2009) Feature-dependent sensitive periods in the development of complex sound representation. J Neurosci 29:5456-5462. CrossRef Medline

Jerger J, Johnson K (1988) Interactions of age, gender, and sensorineural hearing loss on ABR latency. Ear Hear 9:168-176. CrossRef Medline

Johnson CJ, Beitchman JH, Young A, Escobar M, Atkinson L, Wilson B, Brownlie EB, Douglas L, Taback N, Lam I, Wang M (1999) Fourteenyear follow-up of children with and without speech/language impairments: speech/language stability and outcomes. J Speech Lang Hear Res 42:744-760. CrossRef Medline

Kacelnik O, Nodal FR, Parsons CH, King AJ (2006) Training-induced plasticity of auditory localization in adult mammals. PLoS Biol 4:e71. CrossRef Medline

Kang R, Sarro EC, Sanes DH (2014) Auditory training during development mitigates a hearing loss-induced perceptual deficit. Front Syst Neurosci 8:49. CrossRef Medline

Keating P, Dahmen JC, King AJ (2013) Context-specific reweighting of auditory spatial cues following altered experience during development. Curr Biol 23:1291-1299. CrossRef Medline

Keating P, Dahmen JC, King AJ (2015) Complementary adaptive processes contribute to the developmental plasticity of spatial hearing. Nat Neurosci 18:185-187. CrossRef Medline

King AJ, Hutchings ME, Moore DR, Blakemore C (1988) Developmental plasticity in the visual and auditory representations in the mammalian superior colliculus. Nature 332:73-76. CrossRef Medline

King AJ, Parsons CH, Moore DR (2000) Plasticity in the neural coding of auditory space in the mammalian brain. Proc Natl Acad Sci U S A 97: 11821-11828. CrossRef Medline

Knudsen EI (1983) Early auditory experience aligns the auditory map of space in the optic tectum of the barn owl. Science 222:939-942. CrossRef Medline

Knudsen EI (1985) Experience alters the spatial tuning of auditory units in the optic tectum during a sensitive period in the barn owl. J Neurosci 5:3094-3109. Medline

Knudsen EI, Knudsen PF, Esterly SD (1982) Early auditory experience modifies sound localization in barn owls. Nature 295:238-240. CrossRef

Knudsen EI, Knudsen PF, Esterly SD (1984a) A critical period for the recovery of sound localization accuracy following monaural occlusion in the barn owl. J Neurosci 4:1012-1020. Medline

Knudsen EI, Esterly SD, Knudsen PF (1984b) Monaural occlusion alters sound localization during a sensitive period in the barn owl. J Neurosci 4:1001-1011. Medline

Kral A, Hubka P, Heid S, Tillein J (2013) Single-sided deafness leads to unilateral aural preference within an early sensitive period. Brain 136: 180-193. CrossRef Medline

Kronenberger WG, Beer J, Castellanos I, Pisoni DB, Miyamoto RT (2014) Neurocognitive risk in children with cochlear implants. JAMA Otolaryngol Head Neck Surg 140:608-615. CrossRef Medline

Kuhl PK, Williams KA, Lacerda F, Stevens KN, Lindblom B (1992) Linguistic experience alters phonetic perception in infants by 6 months of age. Science 255:606-608. CrossRef Medline

Lin FR, Yaffe K, Xia J, Xue QL, Harris TB, Purchase-Helzner E, Satterfield S, Ayonayon HN, Ferrucci L, Simonsick EM (2013) Hearing loss and cognitive decline in older adults. JAMA Intern Med 173:293-299. CrossRef Medline

Marler P, Tamura M (1964) Culturally transmitted patterns of vocal behavior in sparrows. Science 146:1483-1486. CrossRef Medline

Melcher JR, Kiang NY (1996) Generators of the brainstem auditory evoked potential in cat: III. Identified cell populations. Hear Res 93:52-71. CrossRef Medline

Melcher JR, Guinan JJ Jr, Knudson IM, Kiang NY (1996) Generators of the brainstem auditory evoked potential in cat: II. Correlating lesion sites with waveform changes. Hear Res 93:28-51. CrossRef Medline

Mogdans J, Knudsen EI (1992) Adaptive adjustment of unit tuning to sound localization cues in response to monaural occlusion in developing owl optic tectum. J Neurosci 12:3473-3484. Medline

Mogdans J, Knudsen EI (1993) Early monaural occlusion alters the neural map of interaural level differences in the inferior colliculus of the barn owl. Brain Res 619:29-38. CrossRef Medline

Mogdans J, Knudsen EI (1994) Site of auditory plasticity in the brain stem (VLVp) of the owl revealed by early monaural occlusion. J Neurophysiol 72:2875-2891. Medline

Mogil JS (1999) The genetic mediation of individual differences in sensitivity to pain and its inhibition. Proc Natl Acad Sci U S A 96:7744-7751. CrossRef Medline

Møller AR, Jannetta PJ (1982) Auditory evoked potentials recorded intracranially from the brain stem in man. Exp Neurol 78:144-157. CrossRef Medline

Møller AR, Jannetta PJ (1983) Interpretation of brainstem auditory evoked potentials: results from intracranial recordings in humans. Scand Audiol 12:125-133. CrossRef Medline

Moore BC, Wojtczak M, Vickers DA (1996) Effect of loudness recruitment on the perception of amplitude modulation. J Acoust Soc Am 100:481489. CrossRef

Moore DR, Irvine DR (1981) Plasticity of binaural interaction in the cat inferior colliculus. Brain Res 208:198-202. CrossRef Medline

Moore DR, Hutchings ME, Meyer SE (1991) Binaural masking level differences in children with a history of otitis media. Audiology 30:91-101. CrossRef Medline

Moore DR, Hine JE, Jiang ZD, Matsuda H, Parsons CH, King AJ (1999) Conductive hearing loss produces a reversible binaural hearing impairment. J Neurosci 19:8704-8711. Medline

Mowery TM, Kotak VC, Sanes DH (2014) Transient hearing loss within a critical period causes persistent changes to cellular properties in adult auditory cortex. Cereb Cortex. Advance online publication. Retrieved Feb. 18, 2014. doi: 10.1093/cercor/bhu013. CrossRef Medline

Niparko JK, Tobey EA, Thal DJ, Eisenberg LS, Wang NY, Quittner AL, Fink NE (2010) Spoken language development in children following cochlear implantation. JAMA 303:1498-1506. CrossRef Medline

Penhune VB (2011) Sensitive periods in human development: evidence from musical training. Cortex 47:1126-1137. CrossRef Medline

Pillsbury HC, Grose JH, Hall JW 3rd (1991) Otitis media with effusion in children: binaural hearing before and after corrective surgery. Arch Otolaryngol Head Neck Surg 117:718-723. CrossRef Medline

Pisoni DB, Cleary M (2003) Measures of working memory span and verbal rehearsal speed in deaf children after cochlear implantation. Ear Hear 24 [Suppl]:106S-120S.

Pisoni DB, Kronenberger WG, Roman AS, Geers AE (2011) Measures of digit span and verbal rehearsal speed in deaf children after more than 10 years of cochlear implantation. Ear Hear 32 [Suppl]:60S-74S.

Pittman AL, Lewis DE, Hoover BM, Stelmachowicz PG (2005) Rapid wordlearning in normal-hearing and hearing-impaired children: effects of age, 
receptive vocabulary, and high-frequency amplification. Ear Hear 26: 619-629. CrossRef Medline

Polley DB, Thompson JH, Guo W (2013) Brief hearing loss disrupts binaural integration during two early critical periods of auditory cortex development. Nat Commun 4:2547. CrossRef Medline

Popescu MV, Polley DB (2010) Monaural deprivation disrupts development of binaural selectivity in auditory midbrain and cortex. Neuron 65:718-731. CrossRef Medline

Razak KA, Richardson MD, Fuzessery ZM (2008) Experience is required for the maintenance and refinement of FM sweep selectivity in the developing auditory cortex. Proc Natl Acad Sci U S A 105:4465-4470. CrossRef Medline

Rosen MJ, Sarro EC, Kelly JB, Sanes DH (2012) Diminished behavioral and neural sensitivity to sound modulation is associated with moderate developmental hearing loss. PLoS One 7:e41514. CrossRef Medline

Ryan A (1976) Hearing sensitivity of the mongolian gerbil, Meriones unguiculatis. J Acoust Soc Am 59:1222-1226. CrossRef Medline

Sanes DH, Bao S (2009) Tuning up the developing auditory CNS. Curr Opin Neurobiol 19:188-199. CrossRef Medline

Sarro EC, Sanes DH (2010) Prolonged maturation of auditory perception and learning in gerbils. Dev Neurobiol 70:636-648. CrossRef Medline

Sarro EC, Sanes DH (2011) The cost and benefit of juvenile training on adult perceptual skill. J Neurosci 31:5383-5391. CrossRef Medline

Sarro EC, Sanes DH (2014) Few juvenile auditory perceptual skills correlate with adult performance. Behav Neurosci 128:29-41. CrossRef Medline

Sarro EC, Rosen MJ, Sanes DH (2011) Taking advantage of behavioral changes during development and training to assess sensory coding mechanisms. Ann N Y Acad Sci 1225:142-154. CrossRef Medline

Shannon RV, Zeng FG, Kamath V, Wygonski J, Ekelid M (1995) Speech recognition with primarily temporal cues. Science 270:303-304. CrossRef Medline

Sherman SM, Spear PD (1982) Organization of visual pathways in normal and visually deprived cats. Physiol Rev 62:738-855. Medline

Singh NC, Theunissen FE (2003) Modulation spectra of natural sounds and ethological theories of auditory processing. J Acoust Soc Am 114:33943411. CrossRef Medline
Sohmer H, Feinmesser M, Szabo G (1974) Sources of electrocochleographic responses as studied in patients with brain damage. Electroencephalogr Clin Neurophysiol 37:663-669. CrossRef Medline

Starr A, Hamilton AE (1976) Correlation between confirmed sites of neurological lesions and abnormalities of far-field auditory brainstem responses. Electroencephalogr Clin Neurophysiol 41:595-608. CrossRef Medline

Tobey EA, Thal D, Niparko JK, Eisenberg LS, Quittner AL, Wang NY (2013) Influence of implantation age on school-age language performance in pediatric cochlear implant users. Int J Audiol 52:219-229. CrossRef Medline

Tomlin D, Rance G (2014) Long-term hearing deficits after childhood middle ear disease. Ear Hear 35:e233-e242. CrossRef Medline

Uhlmann RF, Larson EB, Rees TS, Koepsell TD, Duckert LG (1989) Relationship of hearing impairment to dementia and cognitive dysfunction in older adults. JAMA 261:1916-1919. CrossRef Medline

Viemeister NF (1979) Temporal modulation transfer functions based upon modulation thresholds. J Acoust Soc Am 66:1364-1380. CrossRef Medline

Wakefield GH, Viemeister NF (1990) Discrimination of modulation depth of sinusoidal amplitude modulation (SAM) noise. J Acoust Soc Am 88: 1367-1373. CrossRef Medline

Werker JF, Gilbert JH, Humphrey K, Tees RC (1981) Developmental aspects of cross-language speech perception. Child Dev 52:349-355. CrossRef Medline

Wichmann FA, Hill NJ (2001a) The psychometric function: I. Fitting, sampling, and goodness of fit. Percept Psychophys 63:1293-1313. CrossRef Medline

Wichmann FA, Hill NJ (2001b) The psychometric function: II. Bootstrapbased confidence intervals and sampling. Percept Psychophys 63:13141329. CrossRef Medline

Wiesel TN, Hubel DH (1965) Comparison of the effects of unilateral and bilateral eye closure on cortical unit responses in kittens. J Neurophysiol 28:1029-1040. Medline

Wilmington D, Gray L, Jahrsdoerfer R (1994) Binaural processing after corrected congenital unilateral conductive hearing loss. Hear Res 74:99-114. CrossRef Medline 